

\section{Sumário}

Dossiê TEMÁTICO: NOVOS INSTITUTOS JURÍDICOS DE LICITAÇÕES E CONTRATOS 17

I. LicitaÇõEs E CONTRATOS PÚBLICOS: PARTE GERAL. 18

INTEGRATED CONTRACT IN LAW 14.133/2021: NEW LAW, SAME PROBLEMS? A STUDY OF COMPARATIVE LAW .20

Paulo Afonso Cavichioli Carmona, Bruno Ribeiro Marques e Odilon Cavallari

Reajustamento de preços na Nova Lei de Licitações e Contratos Administrativos BRASILEIRA: O "Princípio" Da ANUALIDAde.

Ricardo Silveira Ribeiro e Bráulio Gomes Mendes Diniz

A nova Lei de Licitações, as encomendas tecnológicas e o diálogo competitivo .61 André Dias Fernandes e Débora de Oliveira Coutinho

LiCITAÇÕES, CONTRATOS E O IMPULSO À APRENDIZAGEM PROFISSIONAL: UM ESTUDO SOBRE A CONTRATAÇÃo de APRENDizes no ESTAdo do AMAZONAS, BRAsIL

Emerson Victor Hugo Costa de Sá, Natasha Yasmine Castelo Branco Donadon e Mauro Augusto Ponce de Leão Braga

Licitações, contratos e Modelo Brasileiro de Processo: notas sobre a viabilidade DA UTILIZAÇÃo DE FERRAMENTAS PROCESSUAIS PARA CONFERIR MAIOR EFICIÊNCIA ÀS AQUISIÇÕES PÚBLICAS

Claudio Madureira e Carlos André Luís Araujo

RESOlUÇão DE CONFLITOS COM A ADMINISTRAÇÃo PÚBLICA E A NOVA LEI DE LICITAÇÕES E CONTRATOS: REFORÇO DOS MEIOS ALTERNATIVOS.

Clarissa Sampaio Silva e Danille Maia Cruz

A Adesão do Brasil ao Acordo sobre Contratações Públicas da OMC: entre tabus e DIFICULDADES REAIS

Eduardo Ferreira Jordã e Luiz Filippe Esteves Cunha

II. Accountability e controle

A LEI N. ${ }^{\circ}$ 14.133/2021 E OS NOVOS LIMITES do CONTROLE EXTERNO: A NECESSÁRIA DEFERÊNCIA dos Tribunais de Contas em prol da Administração Pública .................................. 162 Ricardo Schneider Rodrigues

O CONTROLE DAS CONTRATAÇÕES PÚBliCAS E A NOVA LEI DE LICITAÇÕES: O QUE HÁ DE Novo? 183

Leandro Sarai, Flávio Garcia Cabral e Cristiane Rodrigues Iwakura 
Programa de compliance como exigênCia em licitações: ANálises EM Prol da QUALIFICAÇÃo DO PROCESSO LICITATÓRIO NO CONTEXTO DA LEI 14.133/2021.

Cristian Ricardo Wittmann e Anayara Fantinel Pedroso

A NOVA REALIDAde bRASILEIRA DE NECESSIDADE DE PROGRAMAS DE INTEGRIDADE DAS PESSOAS JURÍDICAS LICITANTES EM PROCESSOS LICITATÓRIOS DA ADMINISTRAÇÃO PÚBLICA 227

Fernando Silva Moreira dos Santos e Luiz Fernando de Oriani e Paulillo

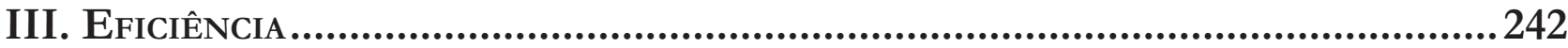

Efficiency contracts in the New Brazilian Procurement Law: conceptual FRAMEWORK AND INTERNATIONAL EXPERIENCE

Floriano de Azevedo Marques Neto, Hendrick Pinheiro e Tamara Cukiert

A gestão de riscos como instrumento para a aplicação efetiva do Princípio Constitucional dA EFICIÊNCIA.

Rafael Rabelo Nunes, Marcela Teixeira Batista Sidrim Perini e Inácio Emiliano Melo Mourão Pinto

IV. Contratação PÚblica No Direito ESTrangeiro

LA ADQUisición de VACUNAS CONTRA LA COVID-19 POR COLOMBIA: ENTRE LA CONFIDENCIALIDAD Y LA FALTA DE TRANSPARENCIA. 284

Gressy Kareny Rojas Cardona e David Mendieta

LA DISCRIMINACIÓN EX POST DE LOS OFERENTES DE UNA LICITACIÓN PÚBLICA COMO INFRACCIÓN ADMINISTRATIVA Y DE LIBRE COMPETÊNCIA 312 Jaime Arancibia Mattar

LA DISCRIMINACIÓN EX POST DE LOS OFERENTES DE UNA LICITACIÓN PÚBLICA COMO INFRACCIÓN ADMINISTRATIVA Y DE LIBRE COMPETÊNCIA..........................................................332 Udochukwu Uneke Alo, Obiamaka Adaeze Nwobu e Alex Adegboye

Outros Temas 348

I. Políticas públicas e institucionalidade

¿Existe El derecho humano a la identidad Cultural de los Migrantes en El Derecho INTERNACIONAL? 351 Juan Jorge Faundes e Glorimar Alejandra Leon Silva

El acceso a la justicia y el debido proceso ante el Tribunal Constitucional y la CorTe Suprema: dos NOCIONES DEL CONTENCIOSO ADMINISTRATIVO CHILENO .384 Pedro Harris Moya 
“Ministrocracia” E DECISÕES INDIVIDUAis CONTRAditórias No Supremo Tribunal FEDERAI

Ulisses Levy Silvério dos Reis e Emilio Peluso Neder Meyer

A POlÍtica de INOVAÇÃo COMO INSTRUMENTO DE REDUÇÃo DAS DESIGUALDADES REGIONAIS NO BRASIL

Caroline Viriato Memória e Uinie Caminha

Conflitos de Competência E A JudicializaÇão da Saúde no Federalismo Brasileiro.447 Jorge Leal Hanai, Luis Antônio Abrantes e Luiz Ismael Pereira

O Ministério Público no enfrentamento dos Reflexos da CRise da Covid-19: UMA

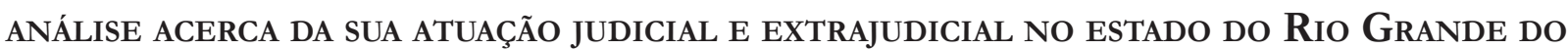
NorTE

Raquel Maria da Costa Silveira, Ana Mônica Medeiros Ferreira, Flávio Luiz Carneiro Cavalcanti e Haroldo Helinski Holanda

A CONSAgRaÇão CONSTITUCIONAL DA POlítica FALIMENTAR

Nuno de Oliveira Fernandes

II. Políticas públicas, grupos vulneráveis e litígios estruturais

LAS LIMITACIONES A LOS DERECHOS DE LOS GRUPOS VULNERABLES Y LOS SUJETOS DE ESPECIAL PROTECCIÓN DURANTE LA PANDEMIA Mary Luz Tobón Tobón

LitígIOS ESTRUTURAIS E A PROTEÇÃO DOS DIREITOS DOS POVOS INDÍGENAS DURANTE A PANDEMIA DE Covid-19: CONTRIBUições do ICCAL

Ana Carolina Lopes Olsen e Bianca M. Schneider van der Broocke

EPISTEMICÍDIO DAS NARRATIVAS NEGRAS E LITÍGIO ESTRUTURAL: INSTRUMENTOS EXTRAJUDICIAIS PARA DISSOLUÇÃO DO PROBLEMA NO SISTEMA EDUCACIONAL .......................................582

Vitor Fonsêca e Caroline da Silva Soares

Trajetórias E DiRETRIZES dAS POlíticas PÚbliCAS NACIONAIS PARA A POPULAÇão INFANTOJUVENIL EM SITUAÇÃO DE RUA...

Wânia Cláudia Gomes Di Lorenzo Lima, Cynthia Xavier de Carvalho e Maria Creusa de A. Borges

Emprendimiento como Fuente de Ingresos para las Víctimas del Conflicto Armado en el Marco de la Ley 1448 de Colombia. Reflexiones de la Implementación en el Valle del Cauca

Saulo Bravo García e Luz Marina Restrepo García

III. Políticas públicas e aÇão Restaurativa. 
JUSTIÇA RESTAURATIVA COMO AÇÃO COMUNICATIVA: EQUILÍBRIO ENTRE SISTEMA E MUNDO DA

Daniela Carvalho Almeida da Costa e Luciana Leonardo Ribeiro Silva de Araújo

JUSTIÇA RESTAURATIVA: ACORDOS E COOPERAÇÃO.................................................668

Samyle Regina Matos Oliveira e Selma Pereira de Santana 


\title{
La discriminación ex post de los oferentes de una licitación pública como infracción administrativa y de libre competência*
}

\author{
A discriminação ex post dos ofertantes \\ de uma licitação pública como infração \\ administrativa e de livre concorrência
}

Jaime Arancibia Mattar**

\section{Resumen}

Este artículo tiene por objeto analizar el principio de igualdad de los oferentes en una licitación con posterioridad a la adjudicación. La razón es que esta variable del principio mucho menos tratada por la doctrina y la jurisprudencia. La metodología utilizada es eminentemente dogmática o teórica a partir del análisis de fuentes primarias legislativas, judiciales y administrativas. Sería el primer artículo sobre la materia publicado en varios países latinoamericanos, incluyendo Chile. La relevancia está dada por la mayor necesidad de asegurar la vigencia del principio de igualdad ante cambios contractuales motivados por hechos sobrevinientes. El interés público exige esta alteración, pero sin afectar la igualdad de los participantes del concurso original, incluso después de finalizado. El respeto de esta simetría concursal tiene relevancia no sólo en derecho constitucional y administrativo, sino también en el derecho económico de la libre competencia. Este trabajo puede producir implicancias sociales en materia de probidad administrativa, pues la necesidad de relicitar los contratos que sufran cambios sustantivos en aras de la igualdad de los concursantes sirve también para prevenir problemas de corrupción.

Palabras clave: Licitación; Igualdad; Concursantes; Post; Adjudicación.

\section{Resumo}

Este artigo tem como objetivo analisar o princípio da igualdade de licitantes em licitação após a adjudicação. O motivo é que essa variável do princípio é muito menos tratada pela doutrina e pela jurisprudência. A metodologia utilizada é eminentemente dogmática ou teórica baseada na análise de fontes primárias legislativas, judiciais e administrativas. Seria o primeiro artigo sobre o tema publicado em vários países da América Latina, incluindo o Chile. A relevância se dá pela maior necessidade de garantir a validade do princípio da igualdade diante de alterações contratuais motivadas por eventos supervenientes. $\mathrm{O}$ interesse público exige essa alteração, mas sem afetar a igualdade dos participantes do concurso original, mesmo após o seu término.

O respeito a essa simetria da insolvência é relevante não apenas no direito

** Ph.D Cambridge University (UK). Profesor de Derecho Administrativo y Constitucional, Director de Departamento de Derecho Público e Director del Programa Magister en Derecho Administrativo de la Universidad de los Andes. Email: jarancibia@uandes.cl
Recebido em 01/08/2021

Aprovado em 14/01/2022 
constitucional e administrativo, mas também no direito econômico da livre concorrência. Este trabalho pode produzir implicações sociais em termos de probidade administrativa, uma vez que a necessidade de relicitar contratos que sofrem alterações substantivas em prol da igualdade dos licitantes serve também para prevenir problemas de corrupção.

Palavras-chave: licitação, igualdade, licitantes, post, adjudicação

\section{Introducción}

Sabido es que todo proceso de licitación pública debe respetar el principio de igualdad de los participantes. Este goza de reconocimiento constitucional, en primer lugar, en las Bases de la Institucionalidad, en virtud del deber del Estado de "asegurar el derecho de las personas a participar con igualdad de oportunidades en la vida nacional" (art. 1 inciso $5^{\circ}$ ). Se manifiesta también en la garantía de que "ni la ley ni autoridad alguna podrán establecer diferencias arbitrarias" (art. $19 \mathrm{~N}^{\circ}$ 2), en la "admisión a todas las funciones y empleos públicos" (art. 19 N 17 ) y en "[l]a no discriminación arbitraria en el trato que deben dar el Estado y sus organismos en materia económica" (art. 19 No 22).

Por su parte, la jurisprudencia constitucional ${ }^{1}$, judicial ${ }^{2}$, y contralora ${ }^{3}$ ha sido pródiga en exigir el principio de igualdad de los postulantes en un proceso licitatorio, sobre todo en materia de contratación pública. Al respecto, la Ley No 18.575, de Bases Generales de la Administración del Estado, establece que "[e]l procedimiento concursal se regirá por los principios de libre concurrencia de los oferentes al llamado administrativo y de igualdad" (art. 9 inciso $2^{\circ}$ ).

En particular, la igualdad de los partícipes en la licitación tiene aplicación no sólo en la elaboración de las bases de licitación, sino también en el trato brindado a los concursantes potenciales (libre concurrencia) y activos durante el procedimiento licitatorio ${ }^{4}$. Incluso más, aunque menos tratada, la igualdad se hace presente durante la etapa de ejecución del contrato por el oferente adjudicado.

\footnotetext{
${ }^{1}$ CHILE. Tribunal Constitucional. Sentencia de Inaplicabilidad Rol No 3.579, Sexto Tribunal de Juicio Oral en lo Penal de Santiago, Santiago, 5 de octubre de 2017. Disponible en www.tribunalconstitucional.cl.; CHILE. Tribunal Constitucional. Sentencia de Inaplicabilidad Rol No 3.702, Universidad de Chile, Santiago, 28 de noviembre de 2018. Disponible en www.tribunalconstitucional. cl.; CHILE. Tribunal Constitucional. Sentencia de Inaplicabilidad Rol No 4.843, Ingenieria y Construcciones Mas Errázuriz Ltda., Santiago, 4 de junio de 2019. Disponible en www.tribunalconstitucional.cl.; CHILE. Tribunal Constitucional. Sentencia de Inaplicabilidad Rol No 5.360, Amec Foster Wheeler International Ingeniería y Construcción Ltda., Santiago, 4 de junio de 2019. Disponible en www.tribunalconstitucional.cl.; CHILE. Tribunal de Defensa de la Libre Competencia. Medida prejudicial adoptada en causa Rol No C-341-2018, Transportes, Inversiones, Inmobiliaria y Servicios Transanber S.A. v Ministerio de Transportes y Telecomunicaciones y otro, Santiago, 25 de enero de 2018. Disponible en www.tdlc.cl.

2 CHILE. Corte Suprema. Sentencia de Recurso de Queja en contra de ministros de Corte de Apelaciones de Santiago, Rol N ${ }^{\circ}$ 7.956-2015, Municipalidad de Pedro Aguirre Cerda, Santiago, 21 de abril de 2016. Disponible en www.pjud.cl.

3 CHILE. Contraloría General de la República. Dictamen No 12.679, Santiago, 11 de marzo de 2005. Disponible en www.contraloria.cl.; CHILE. Contraloría General de la República. Dictamen No 2.907, Santiago, 11 de marzo de 2005. Disponible en www.contraloria.cl.; CHILE. Contraloría General de la República. Dictamen No 20.243, Santiago, 20 de marzo de 2014. Disponible en www. contraloria.cl.; CHILE. Contraloría General de la República. Dictamen No 26.212, Santiago, 19 de mayo de 2009. Disponible en www.contraloria.cl.; CHILE. Contraloría General de la República. Dictamen N 27.268 , Santiago, 20 de mayo de 2010. Disponible en www.contraloria.cl.; CHILE. Contraloría General de la República. Dictamen No 3.686, Santiago, 29 de enero de 2003. Disponible en www.contraloria.cl.; CHILE. Contraloría General de la República. Dictamen No 35.067, Santiago, 23 de septiembre de 1999. Disponible en www.contraloria.cl.; CHILE. Contraloría General de la República. Dictamen No 45.757, Santiago, 21 de agosto de 2009. Disponible en www.contraloria.cl.; CHILE. Contraloría General de la República. Dictamen No 62.483, Santiago, 20 de diciembre de 2004. Disponible en www.contraloria.cl.; CHILE. Contraloría General de la República. Dictamen No 65.392, Santiago, 2 de septiembre de 2016. Disponible en www.contraloria.cl.; CHILE. Contraloría General de la República. Dictamen Nº 67.946, Santiago, 14 de septiembre de 2016. Disponible en www.contraloria.cl.; CHILE. Contraloría General de la República. Dictamen No 7.348 de 2007, Santiago, 13 de febrero de 2007. Disponible en www.contraloria.cl.; CHILE. Contraloría General de la República. Dictamen $\mathrm{N}^{\circ} 71.923$, Santiago, 6 de noviembre de 2013. Disponible en www.contraloria.cl.

${ }^{4}$ CHILE. Corte Suprema. Sentencia de Recurso de Queja en contra de ministros de Corte de Apelaciones de Santiago, Rol No 3.447-2018, Complejo Asistencial Dr. Víctor Ríos Ruiz, Santiago, 2 de agosto de 2018. Disponible en www.pjud.cl.; CHILE. Corte
} 
Esta última exigencia de igualdad admite el calificativo de ex post porque rige con posterioridad al concurso. Consiste en el cumplimiento de los deberes legales regulados por las bases de licitación de modo estricto, con el fin de asegurar que los términos del contrato sean idénticos a los considerados por los concursantes para elaborar sus ofertas. Cualquier apartamiento, desvío o exención relevante respecto de tales términos constituiría una alteración de las reglas del concurso que configuraría un privilegio ilegal del adjudicatario en perjuicio de sus competidores en la licitación.

Este trabajo tiene por objeto desarrollar el principio de igualdad ex post de los partícipes de una licitación pública en el ámbito del derecho administrativo y de la libre competencia. Para tal efecto, su contenido estará dividido en dos secciones. La primera se pronunciará sobre la infracción del principio en materia administrativa, mientras que la segunda se referirá a la infracción a la libre competencia derivada del privilegio ilegal ex post del adjudicatario de la licitación.

\section{El principio de igualdad ex post de los oferentes de una licitación administrativa}

Por regla general, la modificación de los términos de las bases de licitación durante la ejecución del contrato en favor de la empresa adjudicataria constituye un privilegio arbitrario vis a vis el resto de los oferentes. En la práctica, el adjudicatario adquiere la ventaja inmerecida de regirse por un estatuto "a la medida" que fue desconocido por sus competidores al momento de formular sus ofertas. El resto de los concursantes podría haber presentado ofertas diferentes de saber que el contrato iba a cambiar durante su ejecución.

En este sentido, la Corte Suprema ha declarado que un contrato podría ser modificado por caso fortuito o fuerza mayor "[...] siempre y cuando aquello no signifique la afectación de los derechos de los restantes oferentes, a fin de procurar el cumplimiento del principio de igualdad" 5 . Asimismo, la Contraloría General de la República ha sostenido que la alteración ex post de los contratos "implicaría una modificación de la propuesta licitada y, por tanto, una infracción a los principios de estricta sujeción a las bases del concurso y

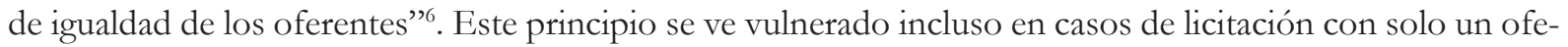
rente, pues la alteración de las bases "[...] afecta, sin duda, al resto de los interesados, independientemente de que éstos, en definitiva, no hayan participado como oferentes en el proceso en comento".?

Estos criterios son consistentes, además, con el Tribunal de Justicia de la Unión Europea, que al efecto ha sostenido que la autoridad licitante está impedida de modificar unilateralmente

una estipulación que, si hubiese figurado en el anuncio de licitación, habría permitido a los licitadores presentar una oferta sustancialmente diferente

$[\ldots]$

dicha práctica supondría inevitablemente la vulneración de los principios de transparencia y de igualdad de trato entre los licitadores, puesto que la aplicación uniforme de las condiciones de licitación y la

\footnotetext{
Suprema. Sentencia de Recurso de Apelación en contra de la Sentencia de la Corte de Apelaciones de Valdivia, Rol N 6.326-2018, Gloria Guerrero, Santiago, 6 de septiembre de 2018. Disponible en www.pjud.cl.; CHILE. Corte Suprema. Sentencia de Reemplazo en Recurso de Casación. Rol No 14.851-2018, Edgardo García. Santiago, 16 de octubre de 2018. Disponible en www.pjud.cl.

5 CHILE. Corte Suprema. Sentencia de Recurso de Apelación de Sentencia de la Corte de Apelaciones de Santiago en Recurso de Amparo Económico, Rol No 6.080-2017, Servicios Alimenticios Hendaya S.A.C. y otros, Santiago, 4 de julio de 2017, c. 35. Disponible en www.pjud.cl.

${ }^{6}$ CHILE. Contraloría General de la República. Dictamen No 11.402, Santiago, 4 de mayo de 2018. Disponible en www.contraloria. $\mathrm{cl}$.

7 CHILE. Contraloría General de la República. Dictamen N 14.445, Santiago, 19 de julio de 2011.Disponible en www.contraloria. cl.; CHILE. Contraloría General de la República. Dictamen No 29.281, Santiago, 13 de mayo de 2013. Disponible en www.contraloria.cl.
} 
objetividad del procedimiento dejarían de estar garantizadas 8 .

Entidad y efectos de la alteración ex post de las reglas del concurso para ser discriminatoria

Sin perjuicio de lo anterior, la jurisprudencia ha formulado dos requisitos adicionales para que la modificación de las bases de licitación sea discriminatoria con respecto al resto de los oferentes. Primero, debe ser de una entidad suficiente; $y$, segundo, debe estar motivada por un hecho que no habría afectado al resto de los oferentes del mismo modo, de haber estado en la posición de adjudicatarios?

Con respecto al primer requisito, el Tribunal de Justicia de la Unión Europea declaró en el caso Pressetext, sobre contrato de prestación de servicios informativos, que el cambio de los términos originales de la licitación se estima sustancial cuando:

a) introduce condiciones que, si hubieran figurado en el procedimiento de adjudicación inicial, habrían permitido la participación de otros licitadores aparte de los inicialmente admitidos o habrían permitido seleccionar una oferta distinta de la inicialmente selecionada

b) amplía el contrato, en gran medida, a servicios inicialmente no previstos; o

c) cambia el equilibrio económico del contrato a favor del adjudicatario del contrato de una manera que no estaba prevista en los términos del contrato inicial ${ }^{10}$.

Para efectos de reconocer esta jurisprudencia a nivel normativo, la Unión Europea dictó posteriormente la Directiva 2014/24/UE sobre contratación pública ${ }^{11}$, cuyo considerando No 107 exige volver a licitar los contratos cuando las condiciones que se pretenden modificar "habrían influido en el resultado del procedimiento, en caso de que hubieran formado parte del procedimiento inicial".

Para concretar esta aspiración, el artículo 72 de la Directiva dispone los casos específicos en que las bases de un contrato podrían ser modificadas sin necesidad de llamar a una nueva licitación. Entre estos destaca la fijación de umbrales de minimis, conforme a los cuales una modificación sería menor o no sustancial cuando no supera "el $10 \%$ del valor inicial del contrato en el caso de los contratos de servicios o de suministros, y el $15 \%$ del valor del contrato inicial en el caso de los contratos de obras" (art. $72 \mathrm{~N}^{\mathrm{o}} 2$ en relación con el art. 4).

Por su parte, la Directiva 2014/23/UE de la Unión Europea ${ }^{12}$, relativa a la adjudicación de contratos de concesión, estableció que una modificación de bases de licitación se entenderá "sustancial", exigiendo por tanto una nueva licitación, en términos muy similares al caso Pressetext citado ${ }^{13}$. En igual sentido, The

\footnotetext{
8 UNIÓN EUROPEA. Sentencia en caso C-496/99, Comisión v CAS Succhi di Frutta. Luxemburgo, 29 de abril de 2004. Disponible en: www.curia.europa.eu Accesso en: 20 ago. 2021; UNIÓN EUROPEA. Sentencia en caso C-91/08, Wall AG v La ville de Francfort-sur-leMain and Frankfurter Entsorgungs- und Service (FES) GmbH. Luxemburgo, 27 de octubre de 2009. Disponible en: www.curia.europa.eu Accesso en: 20 ago. 2021; UNIÓN EUROPEA. Sentencia en caso C-549/14, Finn Frogne A/S contra Rigspolitiet ved Center for Beredskabskommunikation. Luxemburgo, 7 de septiembre de 2016. Disponible en: www.curia.europa.eu Accesso en: 20 ago. 2021.

9 BOLTON, P. Scope for negotiating and/or varying the terms of government contracts awarded by way of a tender process. Stellenbosch Law Review, Centurion, v. 17, n. 2, p. 266-288, 2006.

10 UNIÓN EUROPEA. Sentencia en caso C-454/06, Pressetext Nachrichtenagentur GmbH v Republik Österreich (Bund), APA-OTS Originaltext-Service GmbH and APA Austria Presse Agentur registrierte Genossenschaft mit beschränkter Haftung. Luxemburgo, 19 de junio de 2008. Disponible en: www.curia.europa.eu Accesso en: 20 ago. 2021.

11 UNIÓN EUROPEA. Directiva 2014/24/UE, sobre contratación pública y por la que se deroga la Directiva 2004/18/CE, Parlamento Europeo y Consejo. Bruselas, 28 de marzo de 2014. Disponible en: https://www.boe.es/doue/2014/094/L00065-00242.pdf Accesso en: 20 ago. 2021.

12 UNIÓN EUROPEA. Directiva 2014/23/UE, relativa a la adjudicación de los contratos de concesión, Parlamento Europeo y Consejo. Bruselas, 28 de marzo de 2014. Disponible en: https://www.boe.es/doue/2014/094/L00001-00064.pdf Accesso en: 20 ago. 2021.

13 De acuerdo con estos preceptos, una modificación adquiere el carácter de sustancial cuando "a) "tenga como resultado una concesión materialmente diferente, en cuanto a su carácter, de la celebrada en un principio"; b) "introduzca condiciones que, de haber figurado en el procedimiento inicial de adjudicación de la concesión, habrían permitido la selección de solicitantes distintos de los seleccionados inicialmente o la aceptación de una oferta distinta a la aceptada inicialmente, o habrían atraído a más participantes en el procedimiento de adjudicación de la concesión"; c) "altere el equilibrio económico de la concesión a favor del concesionario en un modo que no estaba previsto en la concesión inicial"; d) "amplíe considerablemente el ámbito de la concesión”; e) "un nuevo concesionario sustituya a aquel al que el poder adjudicador o la entidad adjudicadora había adjudicado inicialmente la concesión en
} 
Public Contracts Regulations $2015^{14}$ del Reino Unido establecen que la modificación de un contrato o de un acuerdo marco durante su vigencia será considerada "sustancial" para los propósitos de requerir una nueva licitación cuando una o más de las mismas condiciones es cumplida ${ }^{15}$.

En Chile, por regla general, las modificaciones a las bases contractuales ex post cuya entidad sería discriminatoria son aquellas que superan umbrales de minimis de variabilidad presupuestaria. Por ejemplo, en contratos de suministro o de prestación de servicios, el Reglamento de la Ley $\mathrm{N}^{\circ} 19.886$ dispone que la modificación del contrato ex post por acuerdo de las partes u otras que establezcan las leyes

Deberá encontrarse prevista en las bases de la licitación. En tal caso, no podrá alterarse la aplicación de los principios de estricta sujeción a las bases y de igualdad de los oferentes, así como tampoco podrá aumentarse el monto del contrato más allá de un $30 \%$ del monto originalmente pactado. ${ }^{16}$

Asimismo, en obra pública a suma alzada, el Reglamento respectivo ${ }^{17}$ dispone que "[el] monto total de las [nuevas] obras que se ejecutan en base a lo señalado en este artículo, no podrá superar el 30\% del valor del contrato inicial" (art. 105 inciso $4^{\circ}$ ). Además, el monto total de los aumentos efectivos de un contrato "no podrán sobrepasar, en su conjunto, el 35\% del monto inicial del contrato, contabilizando las disminuciones convenidas" (art. 106).

Una situación similar rige el contrato de concesión de obra pública. Si la modificación del proyecto excede el presupuesto máximo fijado por la legislación de obras públicas y las bases de licitación, el Ministerio de Obras Públicas debe proceder al término anticipado del contrato de mutuo acuerdo ${ }^{18}$ o unilateralmente ${ }^{19}$, y analizar la posibilidad de llamar a una nueva licitación si concurren ciertas condiciones específicas, entre las que destaca

1) Que los hechos y circunstancias que dan lugar a la necesidad de rediseño o complementación se produzcan con posterioridad a la adjudicación de la concesión y no hayan podido ser previstos al tiempo de su adjudicación. ${ }^{20}$

En este sentido, un laudo arbitral en concesiones de obra pública declaró que

otros casos que los previstos en el apartado 1, letra d)". UNIÓN EUROPEA. Directiva 2014/23/UE, relativa a la adjudicación de los contratos de concesión, Parlamento Europeo y Consejo. Bruselas, 28 de marzo de 2014. Disponible en: https://www.boe.es/doue/2014/094/ L00001-00064.pdf Accesso en: 20 ago. 2021.

${ }_{14}$ REINO UNIDO. The Public Contracts Regulations 2015, Parlamento Británico, UK Statutory Instruments 2015. Londres, 5 de febrero de 2015. Disponible en: http://www.legislation.gov.uk/uksi/2015/102/contents Accesso en: 20 ago. 2021.

15 Regulation 72 (8): “(a)the modification renders the contract or the framework agreement materially different in character from the one initially concluded; (b)the modification introduces conditions which, had they been part of the initial procurement procedure, would have - (i)allowed for the admission of other candidates than those initially selected,(ii)allowed for the acceptance of a tender other than that originally accepted, or (iii)attracted additional participants in the procurement procedure; (c)the modification changes the economic balance of the contract or the framework agreement in favour of the contractor in a manner which was not provided for in the initial contract or framework agreement; (d)the modification extends the scope of the contract or framework agreement considerably; (e)a new contractor replaces the one to which the contracting authority had initially awarded the contract in cases other than those provided for in paragraph (1)(d)". REINO UNIDO. The Public Contracts Regulations 2015, Parlamento Británico, UK Statutory Instruments 2015. Londres, 5 de febrero de 2015. Disponible en: http://www.legislation.gov.uk/uksi/2015/102/ contents Accesso en: 20 ago. 2021.

${ }^{16}$ CHILE. Ministerio de Hacienda. Decreto Supremo No 250, Aprueba reglamento de la Ley No 19.886 de bases sobre contratos administrativos de suministro y prestación de servicios, Santiago, publicado en el Diario Oficial el 24 de septiembre de 2004.

17 CHILE. Ministerio de Obras Públicas. Decreto Supremo No 75 , deroga Decreto Nº15 de 1992 y sus modificaciones posteriores y aprueba Reglamento para Contratos de Obras Públicas, Santiago, publicado en el Diario Oficial el 1 de diciembre de 2004.

${ }_{18}$ CHILE. D.F.L. MOP No 164 de 1991, Ley de Concesiones de Obras Públicas, cuyo texto refundido, coordinado y sistematizado fue fijado por Decreto Supremo No 900, Ministerio de Obras Públicas, Santiago, publicado en el Diario Oficial el 18 de diciembre de 1996. Art. $27 \mathrm{~N}^{\circ} 2$.

19 CHILE. D.F.L. MOP No 164 de 1991, Ley de Concesiones de Obras Públicas, cuyo texto refundido, coordinado y sistematizado fue fijado por Decreto Supremo No 900, Ministerio de Obras Públicas, Santiago, publicado en el Diario Oficial el 18 de diciembre de 1996. Art. $27 \mathrm{~N}^{\circ} 2$, art. 28 ter.

${ }^{20}$ CHILE. D.F.L. MOP No 164 de 1991, Ley de Concesiones de Obras Públicas, cuyo texto refundido, coordinado y sistematizado fue fijado por Decreto Supremo No 900, Ministerio de Obras Públicas, Santiago, publicado en el Diario Oficial el 18 de diciembre de 1996. 
[s]i, una vez celebrado el contrato, pudiese desoírse una regla explícita como la anterior, se atentaría contra el mecanismo de la licitación en su conjunto, el principio de estricta sujeción a las bases y el trato igualitario entre los oferentes. ${ }^{21}$

En cuanto a la exigencia de que el hecho que motiva el cambio no habría afectado al resto de los oferentes estando en la misma posición del adjudicatario, la Contraloría General de la República ha declarado que, para incurrir en discriminación arbitraria de oferentes, el hecho que motiva el cambio de licitación no puede ser uno que "habría afectado de la misma forma a cualquiera que hubiese sido el contratista"22. En este sentido la Comisión Europea consideró que la variación negociada del contrato para modernizar el metro de Londres con posterioridad a la adjudicación no discriminaba arbitrariamente al resto de los oferentes porque "the final results of the process (including the elements negotiated after the selection of the bidders) would not have changed the outcome of the tendering procedure". ${ }^{23}$

En materia probatoria, dado que la modificación de las bases de licitación con posterioridad a la adjudicación es una excepción al principio general de invariabilidad de las reglas del concurso para asegurar la igualdad de los oferentes, el Tribunal de Justicia de la Unión Europea ha declarado que "la carga de la prueba de que existen realmente las circunstancias excepcionales que justifican la excepción incumbe a quien quiera beneficiarse de ellas" ${ }^{\prime 24}$.

Finalmente, la única excepción a la posibilidad de alteración sustancial y ex post las reglas del contrato sería que esta estuviera contemplada en las bases de licitación desde un principio. Al respecto, el derecho comunitario europeo ha previsto que, al proceder de ese modo,

el poder adjudicador garantiza que todos los operadores económicos interesados en participar en ese contrato tengan conocimiento de ello desde el principio y se encuentren así en pie de igualdad en el momento de formular su oferta ${ }^{25}$.

De acuerdo a las consideraciones anteriores, el ilícito administrativo de discriminación arbitraria ex post de los oferentes potenciales y activos de una licitación pública exige una alteración sustancial de las bases concursales, imprevista en estas, que no habría afectado las ofertas presentadas del mismo modo. Corresponde ahora analizar la variante anticompetitiva de esta infracción, de carácter eventual.

\section{Infracción de la libre competencia por privilegio ilegal ex post del adjudicatario}

Que la discriminación arbitraria de demandantes u oferentes de un producto licitado pueda afectar también la libre competencia es un tema pacífico en la doctrina y en la jurisprudencia nacional. Prueba de ello

\footnotetext{
${ }^{21}$ CHILE. Comisión Arbitral de Concesión de Obra Pública, Laudo en caso SC Autopista Vespucio Sur S.A. con MOP, 24 de enero de 2011, c. $16^{\circ}$. Disponible en http:// fiscalia.mop.cl/Paginas/Sentencias.aspx.

22 CHILE. Contraloría General de la República. Dictamen No 1.865, Santiago, 10 de julio de 2019. Disponible en www.contraloria. $\mathrm{cl}$.

23 UNIÓN EUROPEA. Decisión c(2002)3578fin, State Aid N-264/2002, London Underground Public Private Partnership. Bruselas, 2 de octubre de 2002. Disponible en: http://www.justice.gov.md/ Accesso en: 20 ago. 2021.

${ }^{24}$ UNIÓN EUROPEA. Sentencia en caso C-340/02, Commission of the European Communities v French Republic. Luxemburgo, 14 de octubre de 2004. Disponible en www.curia.europa.eu Accesso en: 20 ago. 2021; UNIÓN EUROPEA. Sentencia en casos unidos C-20/01 y C-28-01, Commission of the European Communities v Federal Republic of Germany. Luxemburgo, 10 de abril de 2003. Disponible en: www. curia.europa.eu Accesso en: 20 ago. 2021.

25 UNIÓN EUROPEA. Sentencia en caso C-549/14, Finn Frogne A/S contra Rigspolitiet ved Center for Beredskabskommunikation. Luxemburgo, 7 de septiembre de 2016. Disponible en: www.curia.europa.eu Accesso en: 20 ago. 2021; UNIÓN EUROPEA. Sentencia en caso C-454/06, Pressetext Nachrichtenagentur GmbH v Republik Österreich (Bund), APA-OTS Originaltext-Service GmbH and APA Austria Presse Agentur registrierte Genossenschaft mit beschränkter Haftung. Luxemburgo, 19 de junio de 2008. Disponible en: www.curia.europa.eu Accesso en: 20 ago. 2021; UNIÓN EUROPEA. Sentencia en caso C-496/99, Comisión v CAS Succhi di Frutta. Luxemburgo, 29 de abril de 2004. Disponible en: www.curia.europa.eu Accesso en: 20 ago. 2021.
} 
es que tanto la Fiscalía Nacional Económica (FNE) como el Tribunal de Defensa de la Libre Competencia (TDLC) han ejercido, con validación de la Corte Suprema ${ }^{26}$, poderes normativos, fiscalizadores, acusatorios y resolutivos para resguardar el principio de igualdad de los partícipes de concursos para la adquisición de bienes públicos.

A nivel doctrinal, son variados los trabajos que admiten la competencia de estas instituciones para controlar la legalidad de los procedimientos concursales en relación con el interés público en la libre competencia ${ }^{27}$.

En el caso de la FNE, el trato igualitario de los participantes de un concurso aparece de manifiesto en sus guías dirigidas a la actuación de organismos públicos ${ }^{28}$, donde se sugiere que

[q]ue en la determinación de las variables del proceso de contratación y en el diseño específico de las bases de licitación se evite toda circunstancia o requerimiento que favorezca arbitrariamente a alguna empresa respecto de otras también interesadas en contratar con la Administración del Estado. ${ }^{29}$

Asimismo, esta entidad ha perseguido la responsabilidad de entes públicos que han infringido este deber con resultados lesivos para la libre competencia ${ }^{30}$.

El TDLC, a su vez, ha declarado que

El Estado y sus organismos deben seleccionar a los proveedores de los bienes o servicios que requieren para el ejercicio de sus actividades, así como desarrollar cualquier función que le encomiende el ordenamiento jurídico y que implique su intervención en los mercados, observando las normas de defensa de la libre competencia, de cuya aplicación ninguna norma los exime. ${ }^{31}$

Más adelante, el mismo fallo complementa esta idea señalando que

La circunstancia de que los actos y contratos que se cuestionan en esta sede se realicen con sujeción plena a procedimientos administrativos de contratación con organismos públicos, no implica que dichos actos o contratos no deban sujetarse también a lo preceptuado en la legislación de defensa de la libre competencia que, por lo demás, también es de orden público. Ello por cuanto, si bien es cierto que hay bienes jurídicos que la legislación sobre contratación pública persigue resguardar, concurrentemente pueden verse afectados también otros bienes jurídicos, tales como aquellos que han de ser tutelados en esta sede..$^{32}$

${ }^{26}$ CHILE. Corte Suprema. Sentencia de Reclamación de Sentencia del Tribunal de Defensa de la Libre Competencia, Rol No $7.796-$ 2008, Fiscalía Nacional Económica, Santiago, 27 de mayo de 2009. Disponible en www.pjud.cl.; CHILE. Corte Suprema. Sentencia de Reclamación de Sentencia del Tribunal de Defensa de la Libre Competencia, Rol No 6.100-2010, Puerto Terrestre Los Andes Sociedad Concesionaria S.A., Fisco de Chile, Graneles Chile S.A. y otros, Santiago, 28 de enero de 2011. Disponible en www.pjud.cl.; CHILE. Corte Suprema. Sentencia de Reclamación de Sentencia del Tribunal de Defensa de la Libre Competencia, Rol N $5.505-$ 2008, Empresa de Electricidad de Magallanes S.A., Santiago, 26 de noviembre de 2008. Disponible en www.pjud.cl.

27 ARANCIBIA, Jaime. Control de actos licitatorios ante el Tribunal de Defensa de la Libre Competencia. Revista de Derecho, Valdivia, v. 30, n. 2, p. 301-316, dic. 2017; BÓRQUEZ, Francisco; HELFMANN, Carolina. La contratación pública y la libre competencia. Revista Anales Derecho UC, Santiago, n. 6, p. 99-128, 2011; GARCÍA, William. Los órganos de la administración del estado como sujetos de las multas aplicadas por el Tribunal de Defensa de la Libre Competencia. Revista de Derecho Económico, Santiago, n. 76, p. 125-154, 2016; NEHME, Nicole. Aplicación de las Normas de Defensa de la Competencia a los Organismos de la Administración del Estado. In: TRIBUNAL DE DEFENSA DE LA LIBRE COMPETENCIA (org.). La libre competencia en el Chile del Bicentenario, Santiago: Thomson Reuters, 2011. p. 317-373; VALDÉS, Domingo. Libre competencia y monopolio. Santiago: Jurídica de Chile, 2006.

${ }^{28}$ FISCALÍA NACIONAL ECONÓMICA. Guía sector público y libre competencia. Santiago, junio de 2012. Disponible en: https:// www.fne.gob.cl/wp-content/uploads/2012/06/Guia-final-sector-publico.pdf Accesso en: 20 ago. 2021.

29 FISCALÍA NACIONAL ECONÓMICA. Compras públicas y libre competencia. Santiago, abril de 2011. Disponible en: https://www. fne.gob.cl/wp-content/uploads/2017/11/Material-de-Promocion-1-Compras-publicas-Abr2011.pdf Accesso en: 20 ago. 2021.

${ }^{30}$ CHILE. Tribunal de Defensa de la Libre Competencia. Sentencia No 77/2008 en causa Rol No C-137-07, FNE v Ilustre Municipalidad de Curicó, Santiago, 4 de noviembre de 2008. Disponible en www.tdlc.cl.

31 CHILE. Tribunal de Defensa de la Libre Competencia. Sentencia No 114/2011 en causa Rol No C-206-10, Renzo Droghetti Lobos v Dirección de Compras y Contratación Pública, Santiago, 17 de noviembre de 2011, c. 11․ Disponible en www.tdlc.cl.

32 CHILE. Tribunal de Defensa de la Libre Competencia. Sentencia No 114/2011 en causa Rol No C-206-10, Renzo Droghetti Lobos v Dirección de Compras y Contratación Pública, Santiago, 17 de noviembre de 2011, c. 11º. Disponible en www.tdlc.cl. 
De acuerdo con el concepto anterior, esta magistratura ha dictado instrucciones generales, formulado recomendaciones normativas ${ }^{33}$, y emitido informes especiales ${ }^{34}$ para velar por el respeto de la igualdad de los oferentes en procesos licitatorios ${ }^{35}$. En materia de procedimientos consultivos, ha condicionado la aprobación de bases de licitación a la incorporación de cláusulas que eviten, inter alia, discriminaciones arbitrarias en contra de postulantes potenciales o activos de tales procesos. ${ }^{36}$ Asimismo, en asuntos contenciosos, el TDLC ha adoptado medidas cautelares ${ }^{37}$ y condenado a organismos públicos por haber elaborado bases de licitación que restringen indebidamente la competencia por el producto licitado, excluyendo o discriminando arbitrariamente a potenciales oferentes. ${ }^{38}$

\section{Por su parte, la Corte Suprema ha declarado que}

No debe olvidarse que de un mismo acto pueden derivar consecuencias jurídicas de diversa naturaleza, y que el examen de legalidad ha de verificarse sólo por el órgano al que la ley ha conferido competencia en razón del tipo de la eventual trasgresión. En la especie el asunto de autos está comprendido en la competencia del Tribunal de la Libre Competencia porque el conflicto ha sido planteado en los términos

\footnotetext{
33 CHILE. Tribunal de Defensa de la Libre Competencia. Proposición de Modificación Normativa No $13 / 2011$ en proceso Rol C No 179-08. Santiago, 19 de enero de 2011. Disponible en www.tdlc.cl.

34 CHILE. Tribunal de Defensa de la Libre Competencia. Informe No 10/2014 en Rol NC No 415-13, sobre condiciones para la licitación pública del frente de atraque $\mathrm{N}^{\circ} 1$ o molo del puerto de Iquique, así como el desarrollo y operación de un futuro tercer frente de atraque en dicho puerto, requerido por la Ley No 19.452. Santiago, 10 de enero de 2014. Disponible en www.tdlc. cl.; CHILE. Tribunal de Defensa de la Libre Competencia. Informe $N^{\circ} 11 / 2014$ en Rol NC No 416-13, sobre condiciones para la licitación pública del frente de atraque $\mathrm{N}^{\circ} 1$ del puerto de Antofagasta, requerido por la Ley $\mathrm{N}^{\circ} 19.452$. Santiago, 20 de marzo de 2014. Disponible en www.tdlc.cl.; CHILE. Tribunal de Defensa de la Libre Competencia. Informe N $^{\circ} 14 / 2019$ en Rol NC No 440-17, sobre procedencia de modificar la regla de restricción a la integración vertical establecida en el Dictamen $\mathrm{N}^{\circ} 1209 / 2002$, requerido por la Ley No 19.452. Santiago, 13 de febrero de 2019. Disponible en www.tdlc.cl.; CHILE. Tribunal de Defensa de la Libre Competencia. Informe No 4/2009 en Rol NC N $303-08$, sobre condiciones para la licitación pública de los sitios números 1 y 2 del frente de atraque del puerto de Coquimbo, requerido por la Ley No 19.452. Santiago, 14 de mayo de 2009. Disponible en www. tdlc.cl.;CHILE. Tribunal de Defensa de la Libre Competencia. Informe No 5/2009 en Rol NC No 313-08, sobre condiciones para la licitación pública del frente de atraque $\mathrm{N}^{\circ} 2$ del puerto de Valparaíso, requerido por la Ley $\mathrm{N}^{\circ} 19.452$. Santiago, 29 de septiembre de 2009. Disponible en www.tdlc.cl.; CHILE. Tribunal de Defensa de la Libre Competencia. Informe No 6/2009 en Rol NC No 317-08, sobre condiciones para la licitación pública del frente de atraque Costanera-Espigón del Puerto de San Antonio, requerido por la Ley No 19.452. Santiago, 15 de octubre de 2009. Disponible en www.tdlc.cl.; CHILE. Tribunal de Defensa de la Libre Competencia. Informe $\mathrm{N}^{\circ}$ 8/2012 en Rol NC No 403-12, sobre solicitud de alzamiento de la restricción a la integración horizontal establecida en el Informe $N^{\circ}$ 5/2009, requerido por la Ley No 19.452. Santiago, 22 de noviembre de 2012. Disponible en www.tdlc.cl.

35 CHILE. Tribunal de Defensa de la Libre Competencia. Resolución que establece "Instrucción de carácter general N¹/2006", para el mercado de la recolección, transporte y disposición final de residuos sólidos domiciliarios, aplicables a todo el territorio nacional en Rol NC No 98-05, Santiago, 8 de junio de 2006, p. 8 y 10. Disponible en www.tdlc.cl.

36 CHILE. Tribunal de Defensa de la Libre Competencia. Resolución No 7/2005, Rol NC N $33-04$, Consulta sobre Bases de Licitación de Residuos Sólidos y otros de la I. Municipalidad de San Fernando, Santiago, 30 de mayo de 2005. Disponible en www. tdlc.cl.; CHILE. Tribunal de Defensa de la Libre Competencia. Resolución No 13/2006, Rol NC No 103-05, Consulta de la DGAC sobre Bases Administrativas para el otorgamiento de una concesión para la operación y explotación de una red hidrante destinada al abastecimiento de combustibles y lubricantes, en el Aeropuerto de Chacalluta de la ciudad de Arica, Santiago, 27 de junio de 2006. Disponible en www.tdlc.cl.; CHILE. Tribunal de Defensa de la Libre Competencia. Resolución No 46/2015, Rol NC Nº 425-14, Consulta de Sociedad Ingeniería en Electrónica, Computación y Medicina S.A, Santiago, 22 de abril de 2015. Disponible en www. tdlc.cl.; CHILE. Tribunal de Defensa de la Libre Competencia. Resolución No 52/2018, Rol NC No 438-17, Consulta de Dirección General de Aeronáutica Civil, Santiago, 30 de abril de 2018. Disponible en www.tdlc.cl.

37 Véanse, por ejemplo, las medidas prejudiciales adoptadas en los procedimientos contenciosos siguientes: Roles No C-341-2018 y C-342-2018, CHILE. Tribunal de Defensa de la Libre Competencia. Medida prejudicial adoptada en causa Rol N ${ }^{\circ}$ C-341-2018, Transportes, Inversiones, Inmobiliaria y Servicios Transanber S.A. v Ministerio de Transportes y Telecomunicaciones y otro, Santiago, 25 de enero de 2018. Disponible en www.tdlc.cl.; CHILE. Tribunal de Defensa de la Libre Competencia. Medida prejudicial adoptada en causa Rol No C-342-2018, Demanda Transportes Santín y Cia. Ltda. contra Fisco de Chile y otro, Santiago, 25 de enero de 2018. Disponible en www.tdlc.cl.

38 CHILE. Tribunal de Defensa de la Libre Competencia. Sentencia No 77/2008 en causa Rol No C-137-07, FNE v Ilustre Municipalidad de Curicó, Santiago, 4 de noviembre de 2008. Disponible en www.tdlc.cl. Esta sentencia fue confirmada por CHILE. Corte Suprema. Sentencia de Reclamación de Sentencia del Tribunal de Defensa de la Libre Competencia, Rol No 7.796-2008, Fiscalía Nacional Económica, Santiago, 27 de mayo de 2009. Disponible en www.pjud.cl.; CHILE. Tribunal de Defensa de la Libre Competencia. Sentencia No 93/2010 en causa Rol No C No 183-08, Fiscalía Nacional Económica v EMELAT, Santiago, 6 de enero de 2010. Disponible en www.tdlc.cl. Sentencia confirmada por CHILE. Corte Suprema. Sentencia de Reclamación de Sentencia del Tribunal de Defensa de la Libre Competencia, Rol No 1.022-2010, Fiscalía Nacional Económica, Santiago, 18 de agosto de 2010. Disponible en www.pjud.cl.
} 
señalados en el artículo $3^{\circ}$ del D. L. $N^{\circ} 211$, esto es como un asunto desligado de la legalidad de las bases de licitación. ${ }^{39}$

Cabe precisar, sin embargo, que no toda discriminación arbitraria de oferentes constituye un ilícito anticompetitivo. Para tal efecto, como hemos dicho ${ }^{40}$, es preciso acreditar, además, que esta se produjo en un mercado donde el ente licitante goza de la aptitud o poder de disciplinar el mercado relevante; de modo que cualquier ventaja arbitraria adquirida por un competidor produzca un efecto discriminatorio de oferentes por razones ajenas a la eficiencia, innovación o mejora en la calidad de los productos.

Infracción ex post de la igualdad de los concursantes como ilícito anticompetitivo.

El derecho comparado, particularmente europeo, ha calificado las conductas que se apartan de las bases con posterioridad a la adjudicación del ganador como anticompetitivas, inter alia, por discriminar arbitrariamente al resto de los concursantes. Un referente reciente en esta materia es Sánchez Graells, quien sostiene al respecto que:

The importance of ensuring that competition-distorting decisions are not adopted after award of the contract rests on two factors. First, it will be important in itself to prevent (new) publicly generated distortions of competition. Secondly, it will be instrumental in ensuring the effectiveness of the system of preparation and award of public contracts - which could be easily circumvented by merely 'postponing' competition-restrictive decisions until after the award of the public contract ${ }^{41}$.

A diferencia de lo que ocurre en derecho administrativo y comparado, este tema ha sido poco tratado en latinoamérica en relación con la libre competencia. Sin embargo, podemos ver algunos atisbos en la doctrina de los organismos de libre competencia. Con bastante claridad, el TDLC ha considerado anticompetitiva la cláusula que, una vez publicadas las Bases, permite "desentenderse de criterios objetivos de evaluación de propuestas" " o "potencialmente sin expresión de causa, dejar sin efecto unilateralmente y ex post los requisitos de competencia que efectivamente deben darse en este tipo de processos [...]"43, desde luego porque "una estipulación como esa eleva el riesgo de un comportamiento oportunista o arbitrario" ${ }^{44}$. El TDLC ha instruido también que

deberá prohibirse la modificación posterior de las condiciones y elementos, establecidos en la adjudicación de la licitación, que determinan los precios a público, sin seguir el mismo procedimiento que permitió su asignación original. ${ }^{45}$

\footnotetext{
39 CHILE. Corte Suprema. Sentencia de Reclamación de Sentencia del Tribunal de Defensa de la Libre Competencia, Rol No 6.1002010, Puerto Terrestre Los Andes Sociedad Concesionaria S.A., Fisco de Chile, Graneles Chile S.A. y otros, Santiago, 28 de enero de 2011, c. $6^{\circ}$. Disponible en www.pjud.cl. Ver también CHILE. Corte Suprema. Sentencia de Reclamación de Sentencia del Tribunal de Defensa de la Libre Competencia, Rol N 5.505-2008, Empresa de Electricidad de Magallanes S.A., Santiago, 26 de noviembre de 2008. Disponible en www.pjud.cl.

40 ARANCIBIA, Jaime. Control de actos licitatorios ante el Tribunal de Defensa de la Libre Competencia. Revista de Derecho, Valdivia, v. 30, n. 2, p. 301-316, dic. 2017. p. 301.

41 SÁNCHEZ-GRAELLS, Albert. Public Procurement and the EU Competition Rules. 2. ed. Oxford: Hart Studies in Competition Law, 2015; AURICCHIO, Vito. The problem of discrimination and anti-competitive behaviour in the execution phase of public contracts. Public Procurement Law Review, n. 7, 1998. p. 124.

42 CHILE. Tribunal de Defensa de la Libre Competencia. Sentencia No 77/2008 en causa Rol No C-137-07, FNE v Ilustre Municipalidad de Curicó, Santiago, 4 de noviembre de 2008, c. 61 ${ }^{\circ}$. Disponible en www.tdlc.cl. Esta sentencia fue confirmada por CHILE. Corte Suprema. Sentencia de Reclamación de Sentencia del Tribunal de Defensa de la Libre Competencia, Rol N ${ }^{\circ}$ 7.796-2008, Fiscalía Nacional Económica, Santiago, 27 de mayo de 2009. Disponible en www.pjud.cl.

${ }^{43}$ CHILE. Tribunal de Defensa de la Libre Competencia. Sentencia No 77/2008 en causa Rol No C-137-07, FNE v Ilustre Municipalidad de Curicó, Santiago, 4 de noviembre de 2008, c. 63. Disponible en www.tdlc.cl. Esta sentencia fue confirmada por CHILE. Corte Suprema. Sentencia de Reclamación de Sentencia del Tribunal de Defensa de la Libre Competencia, Rol N ${ }^{\circ}$ 7.796-2008, Fiscalía Nacional Económica, Santiago, 27 de mayo de 2009. Disponible en www.pjud.cl.

44 CHILE. Tribunal de Defensa de la Libre Competencia. Sentencia No 77/2008 en causa Rol No C-137-07, FNE v Ilustre Municipalidad de Curicó, Santiago, 4 de noviembre de 2008, c. $62^{\circ}$. Disponible en www.tdlc.cl. Esta sentencia fue confirmada por CHILE. Corte Suprema. Sentencia de Reclamación de Sentencia del Tribunal de Defensa de la Libre Competencia, Rol N ${ }^{\circ}$ 7.796-2008, Fiscalía Nacional Económica, Santiago, 27 de mayo de 2009. Disponible en www.pjud.cl.

45 CHILE. Tribunal de Defensa de la Libre Competencia. Proposición de Modificación Normativa No 7/2007, contenida en Sentencia No 61/2006 en proceso Rol C Nº 88-06. Santiago, 27 diciembre de 2007. Disponible en www.tdlc.cl.
} 
Asimismo, la modificación ex post de las bases de licitación como conducta anticompetitiva se desprende de la exigencia del TDLC de exigir, en el caso de derechos exclusivos, "[r] ealizar un monitoreo constante y eficaz del uso efectivo u operación regular por parte de las aerolíneas de los Derechos de Tráfico o Frecuencias Aéreas Internacionales que se les hayan adjudicado" ${ }^{46}$.

En efecto, conforme a estos criterios, cualquier modificación sustancial de las reglas del contrato por un órgano administrativo con poder de mercado es anticompetitiva porque, en la práctica, implica "desentenderse" o dejar de cumplir las reglas de competencia en perjuicio del resto de los competidores, que quedan privados o excluidos de la posibilidad de haber ofertado de acuerdo a las nuevas condiciones de operación.

En particular, el TDLC ha declarado que

Para ajustarse a la normativa sobre libre competencia, las licitaciones públicas que otorgan un monopolio (como es el caso de las Bases) deben generar un nivel de competencia ex ante o 'por el mercado' con miras a emular los resultados de un mercado competitivo ex post. ${ }^{47}$

De lo anterior se desprende, entonces, que el monopolio de un adjudicatario no atenta en contra de la libre competencia en la medida que exista respeto a las reglas de competencia ex ante. Cualquier alteración relevante de las mismas constituiría un tratamiento privilegiado ex post que no emula, antes bien, infringe las condiciones de competencia ex ante, afectando de esta forma la igualdad de los concursantes.

A mayor abundamiento, cabe explicar que, en la práctica, todo cambio sustantivo en el que incurre un licitante monopólico equivale a una especie de subsidio discriminatorio y anticompetitivo. Puesto que la adjudicación constituye un acto administrativo de beneficio sujeto al cumplimiento de obligaciones de interés público, la atenuación o mitigación de los mismos configura un escenario de desigualdad ante los bienes públicos. El deber condonado equivale a una deuda impaga que, de no ser cobrada, equivale a un subsidio exclusivo y discriminatorio en favor del adjudicatario.

En términos estrictos de libre competencia, no se observa diferencia entre la exención exclusiva de una obligación establecida en las bases y la exención del pago de derechos municipales por el uso de bienes nacionales que privilegiaba injustamente a ciertos instaladores de infraestructura sanitaria en desmedro de sus competidores. Por tanto, la primera se haría merecedora del mismo reproche que la FNE formuló a la segunda: "ello constituye una discriminación, en perjuicio directo de uno de los actores del mercado respectivo, que entorpece la libre competencia"48.

En igual sentido, Sánchez Graells advierte que la existencia de umbrales de minimis bajo los cuales es posible realizar cambios a las bases concursales con posterioridad a la adjudicación puede igualmente prestarse para otorgar ventajas indebidas al ganador que equivaldrían a subsidios implícitos anticompetitivos ${ }^{49}$. Por

\footnotetext{
46 CHILE. Tribunal de Defensa de la Libre Competencia. Proposición de Modificación Normativa No 09/2009, contenida en Sentencia No 81/2009 en proceso Rol C No 148-07. Santiago, 16 de enero de 2009. Disponible en www.tdlc.cl.

${ }^{47}$ CHILE. Tribunal de Defensa de la Libre Competencia. Resolución No 52/2018, Rol NC No 438-17, Consulta de Dirección General de Aeronáutica Civil, Santiago, 30 de abril de 2018, c. 40. Disponible en www.tdlc.cl. Ver también CHILE. Tribunal de Defensa de la Libre Competencia. Resolución que establece "Instrucción de carácter general No3/2013", que modifica instrucciones de carácter general No 1/2006 para el mercado de la recolección, transporte y disposición final de residuos sólidos domiciliarios, aplicables a todo el territorio nacional, Rol NC No 409-12, Santiago, 21 de marzo de 2013, c. 22 $2^{\circ}$. Disponible en www.tdlc.cl.

48 Esta frase es atribuida a la FNE por CHILE. Tribunal de Defensa de la Libre Competencia. Sentencia No 2/2004 en proceso Rol NC 03-04, Santiago, Solicitud de FNE, 10 de junio de 2004. Disponible en www.tdlc.cl.

49 Part Four, 6, II, A, iii: "In that regard, the application of the principle of competition and the principles of proportionality and good administration may remain instrumental in imposing restrictions on the use of this de minimis clause, particularly where it can result in the granting of undue economic advantages that, in the end, amount to implicit state aid (in the form of unjustified de minimis modifications of contracts that alter the economic balance in favour of the contractor for no good reason). Consequently, this is an area where extreme caution should be exercised by contracting authorities concerned with their integrity and with the avoidance of competition distortions, and one where the involvement of competition authorities in the oversight of contractual modifications could be most effective". SÁNCHEZ-GRAELLS, Albert. Public Procurement and the EU Competition Rules. 2. ed. Oxford: Hart Studies in Competition Law, 2015.
} 
tanto, a esta situación resulta plenamente aplicable la doctrina del TDLC sobre subsidios anticompetitivos que confieren ventajas anticompetitivas:

[...] debe evitarse que este tipo de subsidios constituyan discriminaciones arbitrarias contrarias a la libre competencia en el trato que el Estado brinda a los particulares en materia económica, otorgando beneficios directos para determinados agentes económicos que actúan en mercados específicos y, por lo tanto, no estando establecidos en favor de algún sector, actividad o zona geográfica, como prescribe el artículo $19 \mathrm{~N}^{\circ} 22$ de nuestra Carta Fundamental ${ }^{50}$.

En este sentido, las bases de licitación para la asignación de mercados monopólicos constituyen una simple precisión de los deberes legales del D.L. N 211 para efectos de que una actividad sin competidores se desarrolle igualmente conforme al óptimo social que exige la libre competencia. Al respecto, el TDLC ha declarado que su finalidad

es simplemente velar porque las condiciones de competencia exante aseguren que la ausencia de rivalidad expost se traduzca de todos modos en las más eficientes condiciones de prestación del servicio en términos de precio, cantidad y calidad oferecidas. ${ }^{51}$

Siguiendo este razonamiento, todo incumplimiento de las mismas, antes o después de la adjudicación del bien, constituye también una infracción al D.L. Nº 211.

En otras palabras, si entendemos que las bases de licitación equivalen a "medidas" o "condiciones" bajo las cuales el desempeño de un adjudicatario monopólico será conforme a las normas de libre competencia, no se observa diferencia entre la modificación de esas bases y el de las medidas o condiciones fijadas por el TDLC o propuestas por la FNE para resguardar la libre competencia en el mercado concernido. En consecuencia, la alteración sustancial de las bases en beneficio de ese adjudicatario, en caso de monopolio, constituye también un ilícito anticompetitivo.

Estas consideraciones se ven confirmadas por la interposición de requerimientos por parte de la FNE en contra de empresas adjudicatarias que alteran de facto las normas de las bases de licitación. Así, por ejemplo, el caso FNE contra ATI y otras ${ }^{52}$ consistió en la acusación de empresas accionistas de la concesionaria del puerto de Antofagasta, precisamente, por haber infringido los límites de participación accionaria que les imponían las bases de licitación para la adjudicación de los frentes de atraque portuario. De hecho, según consta en la resolución aprobatoria del acuerdo conciliatorio por parte del TDLC:

Los compromisos asumidos por las partes en el acuerdo conciliatorio están orientados a satisfacer las pretensiones de la FNE en este juicio y precaver un litigio eventual entre las partes, relativo al incumplimiento de las obligaciones que el acto de concesión portuaria impuso a ATI $[\ldots]^{53}$

Por último, desde un punto de vista estrictamente económico, el apego a las normas de licitación originales debe exigirse para evitar posibles ineficiencias debidas a moral hazard. En efecto, según lo demuestra la literatura reciente ${ }^{54}$, la posibilidad de modificar las bases de iure o de facto con posterioridad a la adjudicación puede generar un incentivo perverso para que firmas menos eficientes propongan ofertas ganadoras que les permitan extraer renta anticompetitiva en un escenario ex post.

\footnotetext{
${ }^{50}$ CHILE. Tribunal de Defensa de la Libre Competencia. Proposición de Modificación Normativa No $13 / 2011$ en proceso Rol C No 179-08. Santiago, 19 de enero de 2011. Disponible en www.tdlc.cl.

51 CHILE. Tribunal de Defensa de la Libre Competencia. Sentencia No 138/2014 en causa Rol No C No 256-13, Ramírez y Compañía Limitada v Ministerio de Transportes y Telecomunicaciones, Santiago, 30 de julio de 2014, c. 14º. Disponible en www.tdlc.cl. ${ }^{52}$ CHILE. Tribunal de Defensa de la Libre Competencia. Requerimiento presentado en causa Rol No C-314-2016, FNE v Antofagasta Terminal Internacional (“ATI”), Santiago, 16 de septiembre de 2016. Disponible en www.tdlc.cl.

${ }^{53}$ CHILE. Tribunal de Defensa de la Libre Competencia. Requerimiento presentado en causa Rol No C-314-2016, FNE v Antofagasta Terminal Internacional (“ATI”), Santiago, 16 de septiembre de 2016. Disponible en www.tdlc.cl. Resolución del TDLC que aprueba la conciliación de las partes, de 16 de agosto de 2017.

${ }^{54}$ CHAKRABORTY, Indranil; KHALIL, Fahad; LAWARREE, Jacques. Competitive procurement with ex post Moral Hazard. 2019. Disponible en: https://econ.washington.edu/sites/econ/files/documents/research/chakraborty_khalil_lawarree_apr_19_2019. pdf Accesso en: 24 ago. 2021
} 
Al respecto, el TDLC ha declarado que cuando la Administración del Estado actúa:

Como un ente regulador que asigna derechos o recursos escasos, reemplazando la competencia en el mercado por competencia por el mercado para que el adjudicatario sirva un mercado de manera monopólica por un período de tiempo... el mercado relevante será precisamente la licitación ${ }^{55}$; [e]n los casos en que se adjudica un servicio en condiciones no competitivas mediante una licitación, dicho ámbito queda definido por las bases de licitación y, por lo tanto, el licitante tiene un amplio poder para afectar el funcionamiento del mercado al diseñarlas ${ }^{56}$.

En igual sentido, la FNE ha enfatizado que el acto administrativo que "otorga derechos exclusivos a un operador" y el que "[e]stablece un sistema del licencias o permisos para operar" 57 tienen el potencial de afectar la libre competencia mediante la reducción del número o variedad de actores que participan en el mercado. Asimismo, la Corte Suprema ha sostenido que "el monopolio refiere un concepto absoluto y su esencia no admite, por lo tanto, la entrada de nuevos -en este caso- oferentes". ${ }^{58}$

Por último, la conducta discriminatoria de los entes estatales en el mercado del producto licitado. La FNE ha señalado que existe un ilícito anticompetitivo cuando los operadores actuales gozan de "un trato diferenciado, discriminándolos en relación a nuevos entrantes". ${ }^{59}$ Esta discriminación se produce, ciertamente, cuando un operador monopólico es favorecido con la modificación sustantiva de las bases de licitación, pues estaría gozando de un privilegio ajeno a las reglas competitivas. Dado que el resguardo de la libre competencia depende de la sujeción igualitaria a estas reglas en mercados monopólicos, el órgano administrativo que las altera de modo culposo incurre en responsabilidad por actos lesivos a dicho interés público.

\section{Conclusiones}

De acuerdo a lo expuesto en las secciones anteriores, es posible arribar a las siguientes conclusiones de este trabajo:

1. Por tratarse de un procedimiento administrativo concursal de carácter público, el órgano encargado de una licitación pública está obligado a asegurar el principio de igualdad de los participantes interesados en la adjudicación del contrato.

2. El principio de igualdad de los participantes en concursos públicos rige no sólo la elaboración de las bases de licitación, sino también en el trato brindado a los concursantes potenciales y reales durante la etapa de ejecución del acto de adjudicación conforme a las bases. Esto se traduce en el cumplimiento de los deberes legales regulados por las bases de licitación de modo estricto, con el fin de asegurar que los términos de la relación jurídica pública sean los mismos conforme a los cuales los concursantes elaboraron sus ofertas.

\footnotetext{
55 CHILE. Tribunal de Defensa de la Libre Competencia. Sentencia No 169/2019 en causa Rol No C-335-17, Constructora Luis Navarro SpA v I. Municipalidad de San José de la Mariquina, Santiago, 4 de noviembre de 2008, c. $3^{\circ}$. Disponible en www.tdlc.cl.; CHILE. Tribunal de Defensa de la Libre Competencia. Sentencia No 132/2013 en causa Rol No C-242-12, Sonda S.A. v Servicio de Registro Civil e Identificación, Santiago, 4 de noviembre de 2008, 43․ Disponible en www.tdlc.cl.; CHILE. Tribunal de Defensa de la Libre Competencia. Sentencia No 138/2014 en causa Rol No C No 256-13, Ramírez y Compañía Limitada v Ministerio de Transportes y Telecomunicaciones, Santiago, 30 de julio de 2014, c. $10^{\circ}$. Disponible en www.tdlc.cl.

56 CHILE. Tribunal de Defensa de la Libre Competencia. Sentencia No 38/2006 en causa Rol No C-12-04, Asociación de Exportadores de Chile A.G. v Ultramar Agencia Marítima S.A. y otros, Santiago, 7 de junio de 2006, c. $10^{\circ}$. Disponible en www.tdlc.cl. 57 FISCALÍA NACIONAL ECONÓMICA. Guía sector público y libre competencia. Santiago, junio de 2012. Disponible en: https:// www.fne.gob.cl/wp-content/uploads/2012/06/Guia-final-sector-publico.pdf Accesso en: 20 ago. 2021.

${ }_{58}$ CHILE. Corte Suprema. Sentencia de Reclamación de Sentencia del Tribunal de Defensa de la Libre Competencia, Rol N ${ }^{\circ}$ 47.555-2016, WSP Servicios Postales S.A. y otro con Superintendencia de Salud, Santiago, 4 de octubre de 2017, c. $7^{\circ}$. Disponible en www.pjud.cl.

${ }^{59}$ CHILE. Corte Suprema. Sentencia de Reclamación de Sentencia del Tribunal de Defensa de la Libre Competencia, Rol No 47.555-2016, WSP Servicios Postales S.A. y otro con Superintendencia de Salud, Santiago, 4 de octubre de 2017, c. $7^{\circ}$. Disponible en www.pjud.cl.
} 
3. No toda modificación a las bases durante la operación de la actividad licitada constituye una discriminación arbitraria. Para tal efecto, es preciso que sea de una entidad suficiente, y que esté motivada por un hecho que no habría afectado al resto de los oferentes del mismo modo, de haber estado en la posición de adjudicatarios.

4. Cabe precisar también que no toda discriminación arbitraria de oferentes constituye un ilícito anticompetitivo. Para tal efecto es preciso acreditar, además, que esta se produjo en un mercado donde el licitante o el oferente de la licitación goza de la aptitud o poder de disciplinar el mercado relevante, de modo que cualquier ventaja arbitraria adquirida por un competidor produce un efecto discriminatorio de oferentes por razones ajenas a la eficiencia, innovación o mejora en la calidad de los productos.

5. El derecho comparado, particularmente europeo, ha calificado la modificación de las bases con posterioridad a la adjudicación del ganador como anticompetitivas, inter alia, por discriminar arbitrariamente al resto de los concursantes. Si bien este ilícito ha sido poco tratado en Chile, es posible ver algunos atisbos en la doctrina de los organismos de libre competencia. 


\section{Referencias}

ARANCIBIA, Jaime. Control de actos licitatorios ante el Tribunal de Defensa de la Libre Competencia. Revista de Derecho, Valdivia, v. 30, n. 2, p. 301-316, dic. 2017.

AURICCHIO, Vito. The problem of discrimination and anti-competitive behaviour in the execution phase of public contracts. Public Procurement Law Review, n. 7, 1998.

BOLTON, P. Scope for negotiating and/or varying the terms of government contracts awarded by way of a tender process. Stellenbosch Law Review, Centurion, v. 17, n. 2, p. 266-288, 2006.

BÓRQUEZ, Francisco; HELFMANN, Carolina. La contratación pública y la libre competencia. Revista Anales Derecho UC, Santiago, n. 6, p. 99-128, 2011.

CHAKRABORTY, Indranil; KHALIL, Fahad; LAWARREE, Jacques. Competitive procurement with ex post Moral Hazard. 2019. Disponible en: https://econ.washington.edu/sites/econ/files/documents/research/ chakraborty_khalil_lawarree_apr_19_2019.pdf Accesso en: 24 ago. 2021.

CHILE. Comisión Arbitral de Concesión de Obra Pública, Laudo en caso SC Autopista Vespucio Sur S.A. con MOP, 24 de enero de 2011. Disponible en http:// fiscalia.mop.cl/Paginas/Sentencias.aspx

CHILE. Contraloría General de la República. Dictamen Nº 14.445, Santiago, 19 de julio de 2011.Disponible en www.contraloria.cl.

CHILE. Contraloría General de la República. Dictamen Nº 1.865, Santiago, 10 de julio de 2019. Disponible en www.contraloria.cl.

CHILE. Contraloría General de la República. Dictamen Nº 11.402, Santiago, 4 de mayo de 2018. Disponible en www.contraloria.cl.

CHILE. Contraloría General de la República. Dictamen No 12.679, Santiago, 11 de marzo de 2005. Disponible en www.contraloria.cl.

CHILE. Contraloría General de la República. Dictamen N² 2.907, Santiago, 11 de marzo de 2005. Disponible en www.contraloria.cl.

CHILE. Contraloría General de la República. Dictamen No 20.243, Santiago, 20 de marzo de 2014. Disponible en www.contraloria.cl.

CHILE. Contraloría General de la República. Dictamen No 26.212, Santiago, 19 de mayo de 2009. Disponible en www.contraloria.cl.

CHILE. Contraloría General de la República. Dictamen No 27.268, Santiago, 20 de mayo de 2010. Disponible en www.contraloria.cl.

CHILE. Contraloría General de la República. Dictamen No 29.281, Santiago, 13 de mayo de 2013. Disponible en www.contraloria.cl.

CHILE. Contraloría General de la República. Dictamen No 3.686, Santiago, 29 de enero de 2003. Disponible en www.contraloria.cl.

CHILE. Contraloría General de la República. Dictamen N 35.067, Santiago, 23 de septiembre de 1999. Disponible en www.contraloria.cl.

CHILE. Contraloría General de la República. Dictamen No 45.757, Santiago, 21 de agosto de 2009. Disponible en www.contraloria.cl.

CHILE. Contraloría General de la República. Dictamen No 62.483, Santiago, 20 de diciembre de 2004. Disponible en www.contraloria.cl. 
CHILE. Contraloría General de la República. Dictamen No 65.392, Santiago, 2 de septiembre de 2016. Disponible en www.contraloria.cl.

CHILE. Contraloría General de la República. Dictamen N 67.946, Santiago, 14 de septiembre de 2016. Disponible en www.contraloria.cl.

CHILE. Contraloría General de la República. Dictamen No 7.348 de 2007, Santiago, 13 de febrero de 2007. Disponible en www.contraloria.cl.

CHILE. Contraloría General de la República. Dictamen No 71.923, Santiago, 6 de noviembre de 2013. Disponible en www.contraloria.cl.

CHILE. Corte Suprema. Sentencia de Reclamación de Sentencia del Tribunal de Defensa de la Libre Competencia, Rol N 5.505-2008, Empresa de Electricidad de Magallanes S.A., Santiago, 26 de noviembre de 2008. Disponible en www.pjud.cl.

CHILE. Corte Suprema. Sentencia de Reclamación de Sentencia del Tribunal de Defensa de la Libre Competencia, Rol No 1.022-2010, Fiscalía Nacional Económica, Santiago, 18 de agosto de 2010. Disponible en www.pjud.cl.

CHILE. Corte Suprema. Sentencia de Reclamación de Sentencia del Tribunal de Defensa de la Libre Competencia, Rol No 6.100-2010, Puerto Terrestre Los Andes Sociedad Concesionaria S.A., Fisco de Chile, Graneles Chile S.A. y otros, Santiago, 28 de enero de 2011. Disponible en www.pjud.cl.

CHILE. Corte Suprema. Sentencia de Reclamación de Sentencia del Tribunal de Defensa de la Libre Competencia, Rol No 47.555-2016, WSP Servicios Postales S.A. y otro con Superintendencia de Salud, Santiago, 4 de octubre de 2017. Disponible en www.pjud.cl.

CHILE. Corte Suprema. Sentencia de Reclamación de Sentencia del Tribunal de Defensa de la Libre Competencia, Rol No 7.796-2008, Fiscalía Nacional Económica, Santiago, 27 de mayo de 2009. Disponible en www.pjud.cl.

CHILE. Corte Suprema. Sentencia de Recurso de Apelación de Sentencia de la Corte de Apelaciones de Santiago en Recurso de Amparo Económico, Rol No 6.080-2017, Servicios Alimenticios Hendaya S.A.C. y otros, Santiago, 4 de julio de 2017. Disponible en www.pjud.cl.

CHILE. Corte Suprema. Sentencia de Recurso de Apelación en contra de la Sentencia de la Corte de Apelaciones de Valdivia, Rol No 6.326-2018, Gloria Guerrero, Santiago, 6 de septiembre de 2018. Disponible en www.pjud.cl.

CHILE. Corte Suprema. Sentencia de Recurso de Queja en contra de ministros de Corte de Apelaciones de Santiago, Rol No 3.447-2018, Complejo Asistencial Dr. Víctor Ríos Ruiz, Santiago, 2 de agosto de 2018. Disponible en www.pjud.cl.

CHILE. Corte Suprema. Sentencia de Recurso de Queja en contra de ministros de Corte de Apelaciones de Santiago, Rol No 7.956-2015, Municipalidad de Pedro Aguirre Cerda, Santiago, 21 de abril de 2016. Disponible en www.pjud.cl.

CHILE. Corte Suprema. Sentencia de Reemplazo en Recurso de Casación. Rol No 14.851-2018, Edgardo García. Santiago, 16 de octubre de 2018. Disponible en www.pjud.cl.

CHILE. D.F.L. MOP No 164 de 1991, Ley de Concesiones de Obras Públicas, cuyo texto refundido, coordinado y sistematizado fue fijado por Decreto Supremo No 900, Ministerio de Obras Públicas, Santiago, publicado en el Diario Oficial el 18 de diciembre de 1996.

CHILE. Ley No 18.575, Orgánica Constitucional de Bases Generales de la Administración del Estado, cuyo texto Refundido, Coordinado Y Sistematizado fue fijado por Decreto con Fuerza de Ley No 1-19653, Ministerio Secretaría General de la Presidencia, Santiago, publicado en el Diario Oficial el 15 de febrero de 2018. 
CHILE. Ley $\mathrm{N}^{\circ} \mathrm{N}^{\circ} 19.886$, de bases de los contratos administrativos de suministro y prestación de servicios, Santiago, publicada en el Diario Oficial el 30 de julio de 2003.

CHILE. Ministerio de Hacienda. Decreto Supremo No 250, Aprueba reglamento de la Ley No 19.886 de bases sobre contratos administrativos de suministro y prestación de servicios, Santiago, publicado en el Diario Oficial el 24 de septiembre de 2004.

CHILE. Ministerio de Obras Públicas. Decreto Supremo No 75, deroga Decreto No15 de 1992 y sus modificaciones posteriores y aprueba Reglamento para Contratos de Obras Públicas, Santiago, publicado en el Diario Oficial el 1 de diciembre de 2004.

CHILE. Tribunal Constitucional. Sentencia de Inaplicabilidad Rol No 3.579, Sexto Tribunal de Juicio Oral en lo Penal de Santiago, Santiago, 5 de octubre de 2017. Disponible en www.tribunalconstitucional.cl

CHILE. Tribunal Constitucional. Sentencia de Inaplicabilidad Rol No 3.702, Universidad de Chile, Santiago, 28 de noviembre de 2018. Disponible en www.tribunalconstitucional.cl

CHILE. Tribunal Constitucional. Sentencia de Inaplicabilidad Rol No 4.843, Ingenieria y Construcciones Mas Errázuriz Ltda., Santiago, 4 de junio de 2019. Disponible en www.tribunalconstitucional.cl

CHILE. Tribunal Constitucional. Sentencia de Inaplicabilidad Rol No 5.360, Amec Foster Wheeler International Ingeniería y Construcción Ltda., Santiago, 4 de junio de 2019. Disponible en www.tribunalconstitucional.cl

CHILE. Tribunal de Defensa de la Libre Competencia. Informe No 10/2014 en Rol NC No 415-13, sobre condiciones para la licitación pública del frente de atraque $\mathrm{N}^{\circ} 1$ o molo del puerto de Iquique, así como el desarrollo y operación de un futuro tercer frente de atraque en dicho puerto, requerido por la Ley No 19.452. Santiago, 10 de enero de 2014. Disponible en www.tdlc.cl.

CHILE. Tribunal de Defensa de la Libre Competencia. Informe No 11/2014 en Rol NC No 416-13, sobre condiciones para la licitación pública del frente de atraque $\mathrm{N}^{\circ} 1$ del puerto de Antofagasta, requerido por la Ley No 19.452. Santiago, 20 de marzo de 2014. Disponible en www.tdlc.cl.

CHILE. Tribunal de Defensa de la Libre Competencia. Informe No 14/2019 en Rol NC No 440-17, sobre procedencia de modificar la regla de restricción a la integración vertical establecida en el Dictamen $\mathrm{N}^{\circ}$ 1209/2002, requerido por la Ley No 19.452. Santiago, 13 de febrero de 2019. Disponible en www.tdlc.cl.

CHILE. Tribunal de Defensa de la Libre Competencia. Informe No 4/2009 en Rol NC No 303-08, sobre condiciones para la licitación pública de los sitios números 1 y 2 del frente de atraque del puerto de Coquimbo, requerido por la Ley No 19.452. Santiago, 14 de mayo de 2009. Disponible en www.tdlc.cl.

CHILE. Tribunal de Defensa de la Libre Competencia. Informe No 5/2009 en Rol NC No 313-08, sobre condiciones para la licitación pública del frente de atraque $\mathrm{N}^{\circ} 2$ del puerto de Valparaíso, requerido por la Ley No 19.452. Santiago, 29 de septiembre de 2009. Disponible en www.tdlc.cl.

CHILE. Tribunal de Defensa de la Libre Competencia. Informe No 6/2009 en Rol NC No 317-08, sobre condiciones para la licitación pública del frente de atraque Costanera-Espigón del Puerto de San Antonio, requerido por la Ley No 19.452. Santiago, 15 de octubre de 2009. Disponible en www.tdlc.cl.

CHILE. Tribunal de Defensa de la Libre Competencia. Informe No 8/2012 en Rol NC No 403-12, sobre solicitud de alzamiento de la restricción a la integración horizontal establecida en el Informe $\mathrm{N}^{\circ} 5 / 2009$, requerido por la Ley N ${ }^{o}$ 19.452. Santiago, 22 de noviembre de 2012. Disponible en www.tdlc.cl.

CHILE. Tribunal de Defensa de la Libre Competencia. Medida prejudicial adoptada en causa Rol No C-3412018, Transportes, Inversiones, Inmobiliaria y Servicios Transanber S.A. v Ministerio de Transportes y Telecomunicaciones y otro, Santiago, 25 de enero de 2018. Disponible en www.tdlc.cl. 
CHILE. Tribunal de Defensa de la Libre Competencia. Medida prejudicial adoptada en causa Rol No C-3422018, Demanda Transportes Santín y Cia. Ltda. contra Fisco de Chile y otro, Santiago, 25 de enero de 2018. Disponible en www.tdlc.cl.

CHILE. Tribunal de Defensa de la Libre Competencia. Proposición de Modificación Normativa No 13/2011 en proceso Rol C No 179-08. Santiago, 19 de enero de 2011. Disponible en www.tdlc.cl.

CHILE. Tribunal de Defensa de la Libre Competencia. Proposición de Modificación Normativa $\mathrm{N}^{\circ}$ 09/2009, contenida en Sentencia No 81/2009 en proceso Rol C No 148-07. Santiago, 16 de enero de 2009. Disponible en www.tdlc.cl.

CHILE. Tribunal de Defensa de la Libre Competencia. Proposición de Modificación Normativa No 7/2007, contenida en Sentencia No 61/2006 en proceso Rol C No 88-06. Santiago, 27 diciembre de 2007. Disponible en www.tdlc.cl.

CHILE. Tribunal de Defensa de la Libre Competencia. Requerimiento presentado en causa Rol No C-3142016, FNE v Antofagasta Terminal Internacional (“ATI”), Santiago, 16 de septiembre de 2016. Disponible en www.tdlc.cl.

CHILE. Tribunal de Defensa de la Libre Competencia. Resolución No 7/2005, Rol NC Nº 33-04, Consulta sobre Bases de Licitación de Residuos Sólidos y otros de la I. Municipalidad de San Fernando, Santiago, 30 de mayo de 2005. Disponible en www.tdlc.cl.

CHILE. Tribunal de Defensa de la Libre Competencia. Resolución No 13/2006, Rol NC No 103-05, Consulta de la DGAC sobre Bases Administrativas para el otorgamiento de una concesión para la operación y explotación de una red hidrante destinada al abastecimiento de combustibles y lubricantes, en el Aeropuerto de Chacalluta de la ciudad de Arica, Santiago, 27 de junio de 2006. Disponible en www.tdlc.cl.

CHILE. Tribunal de Defensa de la Libre Competencia. Resolución No 46/2015, Rol NC No 425-14, Consulta de Sociedad Ingeniería en Electrónica, Computación y Medicina S.A, Santiago, 22 de abril de 2015. Disponible en www.tdlc.cl.

CHILE. Tribunal de Defensa de la Libre Competencia. Resolución No 52/2018, Rol NC No 438-17, Consulta de Dirección General de Aeronáutica Civil, Santiago, 30 de abril de 2018. Disponible en www.tdlc.cl.

CHILE. Tribunal de Defensa de la Libre Competencia. Resolución que aprueba conciliación de las partes en causa Rol No C-314-2016, FNE v Antofagasta Terminal Internacional ("ATI"), Santiago, 16 de agosto de 2017. Disponible en www.tdlc.cl.

CHILE. Tribunal de Defensa de la Libre Competencia. Resolución que establece "Instrucción de carácter general N¹/2006", para el mercado de la recolección, transporte y disposición final de residuos sólidos domiciliarios, aplicables a todo el territorio nacional en Rol NC No 98-05, Santiago, 8 de junio de 2006. Disponible en www.tdlc.cl.

CHILE. Tribunal de Defensa de la Libre Competencia. Resolución que establece "Instrucción de carácter general N³/2013", que modifica instrucciones de carácter general $N^{\circ} 1 / 2006$ para el mercado de la recolección, transporte y disposición final de residuos sólidos domiciliarios, aplicables a todo el territorio nacional, Rol NC No 409-12, Santiago, 21 de marzo de 2013. Disponible en www.tdlc.cl.

CHILE. Tribunal de Defensa de la Libre Competencia. Sentencia No 138/2014 en causa Rol No C No 25613, Ramírez y Compañía Limitada v Ministerio de Transportes y Telecomunicaciones, Santiago, 30 de julio de 2014. Disponible en www.tdlc.cl.

CHILE. Tribunal de Defensa de la Libre Competencia. Sentencia No 114/2011 en causa Rol No C-206-10, Renzo Droghetti Lobos v Dirección de Compras y Contratación Pública, Santiago, 17 de noviembre de 2011. Disponible en www.tdlc.cl. 
CHILE. Tribunal de Defensa de la Libre Competencia. Sentencia No 77/2008 en causa Rol N ${ }^{\circ}$ C-137-07, FNE v Ilustre Municipalidad de Curicó, Santiago, 4 de noviembre de 2008. Disponible en www.tdlc.cl.

CHILE. Tribunal de Defensa de la Libre Competencia. Sentencia No 2/2004 en proceso Rol NC 03-04, Santiago, Solicitud de FNE, 10 de junio de 2004. Disponible en www.tdlc.cl.

CHILE. Tribunal de Defensa de la Libre Competencia. Sentencia No 93/2010 en causa Rol No C Nº 183-08, Fiscalía Nacional Económica v EMELAT, Santiago, 6 de enero de 2010. Disponible en www.tdlc.cl.

CHILE. Tribunal de Defensa de la Libre Competencia. Sentencia No 169/2019 en causa Rol No C-335-17, Constructora Luis Navarro SpA v I. Municipalidad de San José de la Mariquina, Santiago, 4 de noviembre de 2008. Disponible en www.tdlc.cl.

CHILE. Tribunal de Defensa de la Libre Competencia. Sentencia No 132/2013 en causa Rol No C-242-12, Sonda S.A. v Servicio de Registro Civil e Identificación, Santiago, 4 de noviembre de 2008. Disponible en www.tdlc.cl.

CHILE. Tribunal de Defensa de la Libre Competencia. Sentencia No 38/2006 en causa Rol No C-12-04, Asociación de Exportadores de Chile A.G. v Ultramar Agencia Marítima S.A. y otros, Santiago, 7 de junio de 2006. Disponible en www.tdlc.cl.

FISCALÍA NACIONAL ECONÓMICA. Compras públicas y libre competencia. Santiago, abril de 2011. Disponible en: https://www.fne.gob.cl/wp-content/uploads/2017/11/Material-de-Promocion-1-Compras-publicas-Abr2011.pdf Accesso en: 20 ago. 2021.

FISCALÍA NACIONAL ECONÓMICA. Guía sector público y libre competencia. Santiago, junio de 2012. Disponible en: https://www.fne.gob.cl/wp-content/uploads/2012/06/Guia-final-sector-publico.pdf Accesso en: 20 ago. 2021.

GARCÍA, William. Los órganos de la administración del estado como sujetos de las multas aplicadas por el Tribunal de Defensa de la Libre Competencia. Revista de Derecho Económico, Santiago, n. 76, p. 125-154, 2016.

NEHME, Nicole. Aplicación de las Normas de Defensa de la Competencia a los Organismos de la Administración del Estado. In: TRIBUNAL DE DEFENSA DE LA LIBRE COMPETENCIA (org.). La libre competencia en el Chile del Bicentenario, Santiago: Thomson Reuters, 2011. p. 317-373.

REINO UNIDO. The Public Contracts Regulations 2015, Parlamento Británico, UK Statutory Instruments 2015. Londres, 5 de febrero de 2015. Disponible en: http://www.legislation.gov.uk/uksi/2015/102/contents Accesso en: 20 ago. 2021.

SÁNCHEZ-GRAELLS, Albert. Public Procurement and the EU Competition Rules. 2. ed. Oxford: Hart Studies in Competition Law, 2015.

UNIÓN EUROPEA. Decisión c(2002)3578fin, State Aid N-264/2002, London Underground Public Private Partnership. Bruselas, 2 de octubre de 2002. Disponible en: http://www.justice.gov.md/ Accesso en: 20 ago. 2021.

UNIÓN EUROPEA. Directiva 2014/23/UE, relativa a la adjudicación de los contratos de concesión, Parlamento Europeo y Consejo. Bruselas, 28 de marzo de 2014. Disponible en: https://www.boe.es/doue/2014/094/ L00001-00064.pdf Accesso en: 20 ago. 2021.

UNIÓN EUROPEA. Directiva 2014/24/UE, sobre contratación pública y por la que se deroga la Directiva 2004/18/ CE, Parlamento Europeo y Consejo. Bruselas, 28 de marzo de 2014. Disponible en: https://www.boe.es/ doue/2014/094/L00065-00242.pdf Accesso en: 20 ago. 2021.

UNIÓN EUROPEA. Sentencia en caso C-340/02, Commission of the European Communities v French Republic. Luxemburgo, 14 de octubre de 2004. Disponible en www.curia.europa.eu Accesso en: 20 ago. 2021. 
UNIÓN EUROPEA. Sentencia en caso C-454/06, Pressetext Nachricbtenagentur GmbH v Republik Österreich (Bund), APA-OTS Originaltext-Service GmbH and APA Austria Presse Agentur registrierte Genossenschaft mit beschränkter Haftung. Luxemburgo, 19 de junio de 2008. Disponible en: www.curia.europa.eu Accesso en: 20 ago. 2021.

UNIÓN EUROPEA. Sentencia en caso C-496/99, Comisión v CAS Succhi di Frutta. Luxemburgo, 29 de abril de 2004. Disponible en: www.curia.europa.eu Accesso en: 20 ago. 2021.

UNIÓN EUROPEA. Sentencia en caso C-549/14, Finn Frogne A/S contra Rigspolitiet ved Center for Beredskabskommunikation. Luxemburgo, 7 de septiembre de 2016. Disponible en: www.curia.europa.eu Accesso en: 20 ago. 2021.

UNIÓN EUROPEA. Sentencia en caso C-91/08, Wall AG v La ville de Francfort-sur-le-Main and Frankfurter Entsorgungs- und Service (FES) GmbH. Luxemburgo, 27 de octubre de 2009. Disponible en: www.curia.europa.eu Accesso en: 20 ago. 2021.

UNIÓN EUROPEA. Sentencia en casos unidos C-20/01 y C-28-01, Commission of the European Communities v Federal Republic of Germany. Luxemburgo, 10 de abril de 2003. Disponible en: www.curia.europa.eu Accesso en: 20 ago. 2021.

VALDÉS, Domingo. Libre competencia y monopolio. Santiago: Jurídica de Chile, 2006. 
Para publicar na revista Brasileira de Políticas Públicas, acesse o endereço eletrônico www.rbpp.uniceub.br

Observe as normas de publicação, para facilitar e agilizar o trabalho de edição. 